\title{
KNOWLEDGE, ATTITUDE AND BARRIERS TO THE UTILIZATION OF EMERGENCY CONTRACEPTIVES AMONG FEMALE STUDENTS OF THE UNIVERSITY FOR DEVELOPMENT STUDIES: A CROSS-SECTIONAL STUDY
}

\author{
${ }^{1}$ Shamsu-Deen, Z., ${ }^{1}$ Sufyan, B. S. and ${ }^{2}$ Issah, F. \\ ${ }^{I}$ Department of Population and Reproductive Health, School of Public Health, University for Development Studies. Box 1883, \\ Tamale, N/R, Ghana. \\ ${ }^{2}$ Ghana Health Service, Tema General Hospital, Grater Accra Region. Box 466.
}

Corresponding author's Email address: $\underline{\text { bsuara@ } \mathrm{uds.edu.gh}}$

\begin{abstract}
Unintended and unwanted pregnancy are a public health threats among young women and girls in developing countries including Ghana. Despite all the public health interventions, the effectiveness of the use of emergency contraceptives (ECS) to avert unintended pregnancies is still low in Ghana. Little is known about the knowledge, attitude, and barriers to ECs utilization in Ghana. Therefore, the objective of the study was to investigate the knowledge, attitudes, and barriers to the utilization of ECs among female students of the University for Development Studies, Tamale. A total of 309 female students of reproductive age were selected using a simple random approach. A descriptive cross-sectional study design was used for the study. Also, a semi-structured questionnaire was used to collect data on knowledge, attitudes, and barriers to the utilization of ECs. Frequency and percentage distribution of the sociodemographic factors, and behavioral and attitude variables of EC variables were computed using the SPSS software (version 20). Overall, the majority (65.0\%) of the participants showed sufficient knowledge of ECs. Also, 54.0\% of the respondents had a good attitude toward EC. An assessment of the reasons for not using any form of ECs revealed that some of them wanted pregnancy (26.6\%), lacked knowledge about ECs (18.1\%), and partner refusal (4.3\%). Also, religious beliefs $(37.2 \%)$ were barriers to the utilization of ECs. In conclusion, the study found a high level of knowledge and a good attitude toward ECs among the study participants. However, partner refusal and religious beliefs were mentioned as barriers to the utilization of ECs. Therefore, we recommend that the health authorities in charge of reproductive health education should liaise with religious leaders as they could partner in the creation of awareness of EC.
\end{abstract}

Keywords: Emergency Contraceptive, Knowledge, Attitude, Barriers, utilization.

\section{Introduction}

Globally, the rates of unintended pregnancies are high (Bearak et al., 2018), which pose a major public health problem to several nations (Sedgh et al., 2014; SmithBattle \& Leonard, 2012; Thomas \& Cameron, 2013; Trussell, 2007). Worldwide, about $44 \%$ of all pregnancies are unintended (Bearak et al., 2018). Previous studies have shown that even in the developed countries (Finer \& Henshaw, 2006; Ganatra et al., 2017; Lakha \& Glasier, 2006), and more recently in Ghana (Ameyaw, 2018), the prevalence of unintended pregnancies is high. The health implications and the economic cost of unintended pregnancies are enormous (Bahk et al., 2015; SmithBattle \& 
Leonard, 2012; Thomas \& Cameron, 2013; Trussell, 2007). For instance, unintended pregnancies are associated with increased levels of household stress (Le et al., 2014), poor life satisfaction (Bahk et al., 2015), high school withdrawal rates (Ameryoun et al., 2011), a higher crime rate (Sonfield et al., 2011), and an increased risk of abortions (Major et al., 2009).

Although the causes of unintended pregnancies are complex, unprotected sexual intercourse is a predisposing factor. Therefore, to prevent unintended pregnancies following unprotected sexual intercourse, the ECs are recommended. These methods are to be used within 5 days or earlier after the act of unprotected sexual intercourse. The methods include the copperbearing intrauterine devices (IUDs), and the emergency contraceptive pills (ECPs) (GemzellDanielsson \& Marions, 2004; Landgren et al., 1989; World Health Organization, 2020).

The level of awareness of the ECs among university and college students have been reported widely in various countries, including some African nations (Abera, 2014; Ahmed et al., 2012; Byamugisha et al., 2006; Fikre et al., 2020; Mekonnen et al., 2017; Nasir \& Pharm, 2010; Shiferaw et al., 2016; Tamire \& Enqueselassie, 2007; Tessema \& Hinsermu, 2015; Tilahun et al., 2011; Davis et al., 2020; Dorairajan et al., 2015; Gebrehiwot et al., 2013; Tesfa, 2015; Yen et al., 2015). Also, among university students in the southern part of Ghana, the knowledge and attitude of students on the ECs have been reported (Addo \& Tagoe-Darko, 2009; Baiden et al., 2002; Darteh \& Doku, 2016). However, such data are lacking among University students in the Northern part of the country, which has created a knowledge gap.
The university students in the southern and northern parts of the country may be exposed to different cultural settings. Therefore, it is important to understand the knowledge level and attitude of the students in a northern university regarding the utilization of ECs. Notwithstanding this knowledge gap, a previous study was conducted among the general population of women in a city within the Northern Zone (Amalba et al., 2014). However, students in the university may have different socioeconomic characteristics, and varying sexual behaviors compared to the general population. In this vein, there is the need to evaluate the level of awareness of ECs among the students.

Further, an understanding of the knowledge, attitude, and the reasons for not using ECs among a young female university population may aid in the formulation of policies that will help to reduce the incidence of unintended pregnancies. Unintended pregnancies among tertiary students may lead to school dropouts due to economic, social, and health consequences (Ameryoun et al., 2011). Hence, the objective of this study was to determine the knowledge, attitude, and barriers to ECs utilization among students in the University for Development Studies, in Northern Region, Tamale.

\section{Materials and Methods}

\section{Study area}

The study was conducted at the University for Development Studies in Tamale, Ghana. The University is the biggest University in the northern part of Ghana. It is located in Dungu in the Tamale metropolis. Figure 1 below illustrates the location of the University within the Tamale Metropolis. 


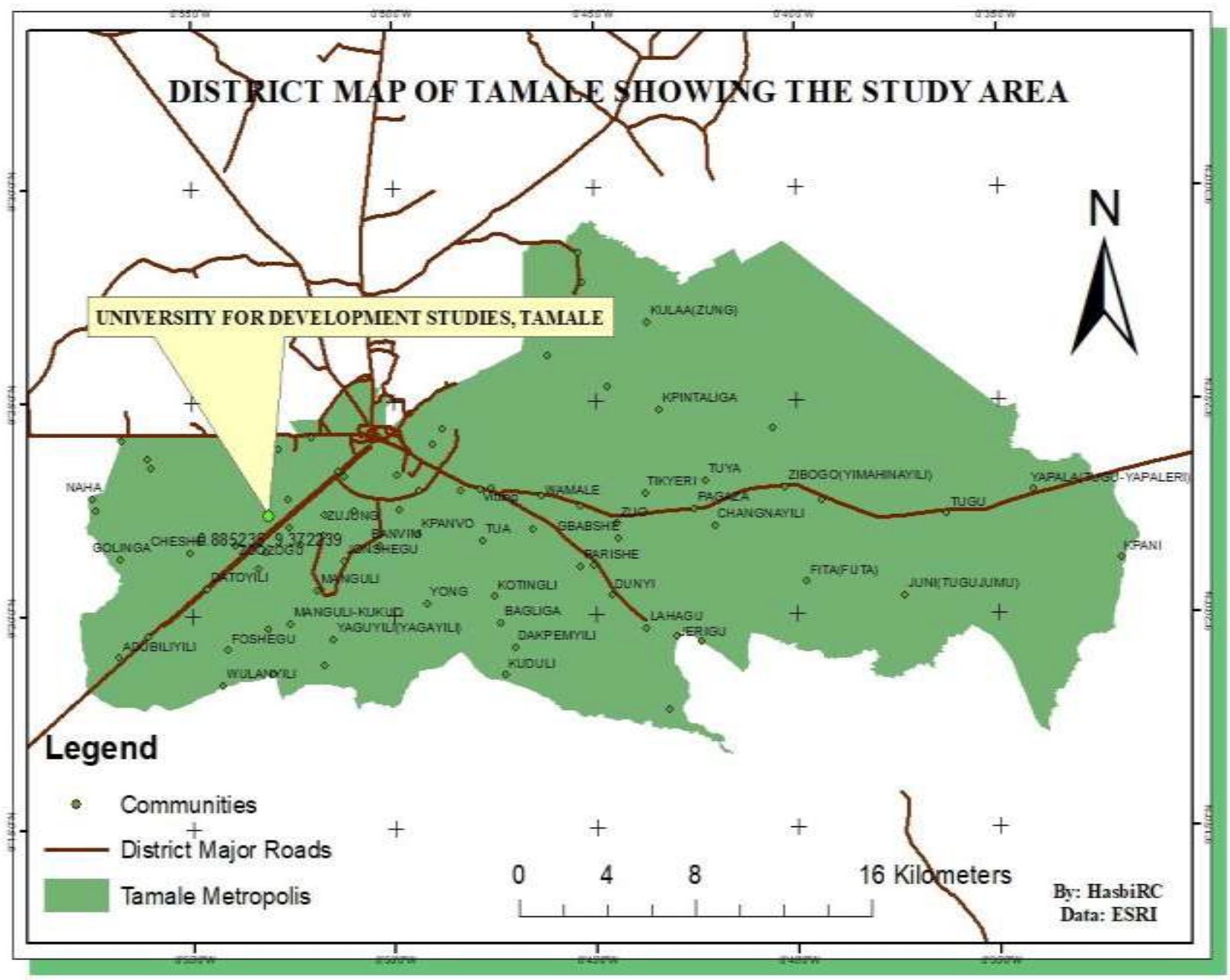

Figure 1. Location of the University for Development Studies, Tamale Campus within the Tamale Metropolis

\section{Sample size}

A descriptive cross-sectional study design was adopted for the study using mixed-methods. The mixed-method allows for the assessment of both quantitative and qualitative data in which the weaknesses of the individual methods may compensate for each other. In total, 309 female students were randomly selected from the University for Development Studies, Tamale Campus. The above sample size (309) for the study was calculated based on a standardized protocol for calculating sample sizes for cross-sectional study designs (Charan \& Biswas, 2013). The study was conducted between March and July 2020. A selfadministered structured questionnaire was the main quantitative tool used to obtain data on the sociodemographic characteristics and background information of the respondents, knowledge, attitudes, and the challenges in using ECs. Copies of the questionnaire were sent to the students through their emails and they returned them afterwards. For the qualitative data, in-depth individual interviews were conducted using an indepth interview guide. Topics included knowledge, attitudes about the experiences in using emergency 
contraceptives, and the challenges in the utilization of ECs. Due to the COVID-19 pandemic, the interviews were conducted through mobile phone calls, and their voices were recorded and transcribed. The average interview length was 50 minutes. All interviews were conducted in English Language. Three researchers who were trained in qualitative interviewing were used for the interviews. Nine students were selected and used for the qualitative studies. The consent of all participants was sought before data collection. Only registered female students of the University were eligible to participate in the study.

\section{Knowledge assessment in EC utilization}

In the assessment of the knowledge of the participants in the EC utilization, a set of questions were asked to elicit their views on best practices. (1) best time EC works, (2) effectiveness of EC, (3) safety of EC, (4) recommended number of doses of EC pills, (5) indicators of EC, and (6) interval between EC pills utilization. A response that was mentioned by a respondent which was consistent with available literature was scored one (1), and responses that were not supported by literature (wrong response), no response, and 'I don't know", response were all scored zero (0). In the end, those who obtained $50 \%$ or more of correct answers were said to have sufficient knowledge of ECs. However, participants who obtained a cumulative score of less than $50 \%$ of the total number of questions were said to have insufficient knowledge of ECs.

\section{Attitude assessment in EC utilization}

To estimate the attitude of participants towards EC utilization, a number of questions were asked to identify from them if: using EC will not cause infertility, using EC after unsafe sex is helpful, EC utilization creates a lack of confidence between partners, is it a good idea to avail EC to all women, is it a sin to use EC method, believe EC may hurt the baby if it does not work, willingness to use EC in the near future, emergency contraceptives cannot protect one from sexually transmitted infections, emergency contraceptives should be used only once every month, emergency contraceptive pills can fail, and emergency contraception cannot be used as a regular form of family planning taken after unprotected sex. A standard scoring scale was adapted from a previous study by Kgosiemang \& Blitz, (2018), and modified for the present study on a 3-point Likert scale (agree, neutral, disagree). A correct response was assigned 3 points, otherwise (neutral or disagree) was assigned 0 (zero). In the end, participants who had a mean of 1.5 and above were said to have a good attitude towards ECs, and those who scored less than 1.5 (mean) were classified as having a poor attitude towards ECs.

\section{Data analysis}

The frequency and percentage distribution of all quantitative data were calculated using SPSS version 24, and the results were presented in frequencies using tables and a bar chart while the qualitative data was analyzed using content and thematic analysis.

\section{Results}

The socio-demographic characteristics of the respondents are shown in Table 1. In this study, majority $(78.3 \%)$ of the participants were within the age group of 20 to 29 years. Similarly, a majority (53.4\%) of them were Muslims. Those who were Christians represented $46.6 \%$. On marital status, the majority $(84.1 \%)$ of the students had never married. Regarding the level of education of mothers of the students, most (36.9\%) had no formal education, $23.6 \%$ of them had secondary education, $20.7 \%$ had primary education, and only $18.8 \%$ had attained tertiary education. Regarding the fathers' educational level, it was observed that $31.4 \%$ of their fathers had tertiary education, $29.1 \%$ had no form of education, $30.7 \%$ had secondary education, and $8.7 \%$ had education up to primary school. 
Table 1: Socio demographic characteristics of selected female students in the University for Development Studies.

\begin{tabular}{|c|c|c|c|}
\hline Variables & Categories & Frequencies & Percentage (\%) \\
\hline \multirow[t]{3}{*}{ Age } & $<20$ years & 53 & 17.2 \\
\hline & 20 to 29 years & 242 & 78.3 \\
\hline & 30 to 39 years & 14 & 4.5 \\
\hline \multirow[t]{6}{*}{ Level } & Level 100 & 34 & 11.0 \\
\hline & Level 200 & 93. & 30.1 \\
\hline & Level 300 & 55 & 17.8 \\
\hline & Level 400 & 98 & 31.7 \\
\hline & Level 500 & 13 & 4.2 \\
\hline & Level 600 & 16 & 5.2 \\
\hline \multirow[t]{2}{*}{ Residence } & Campus & 148 & 47.9 \\
\hline & Out of campus & 161 & 52.1 \\
\hline \multirow[t]{2}{*}{ Religion } & Christianity & 144 & 46.6 \\
\hline & Islam & 165 & 53.4 \\
\hline \multirow[t]{2}{*}{ Marital status } & Married & 49 & 15.9 \\
\hline & Single & 260 & 84.1 \\
\hline \multirow[t]{5}{*}{ Ethnicity } & Akan & 59 & 19.1 \\
\hline & Dagomba & 72 & 23.3 \\
\hline & Dagarti & 51 & 16.5 \\
\hline & Frafra & 27 & 8.7 \\
\hline & Others & 100 & 32.4 \\
\hline \multirow[t]{3}{*}{ Faculty } & SMHS & 87 & 28.2 \\
\hline & SAHS & 135 & 43.7 \\
\hline & FOE & 87 & 28.2 \\
\hline \multicolumn{4}{|c|}{$\begin{array}{l}\text { Mother's educational } \\
\text { Status }\end{array}$} \\
\hline & No formal education & 114 & 36.9 \\
\hline & Primary & 64 & 20.7 \\
\hline & Secondary & 73 & 23.6 \\
\hline & Tertiary & 58 & 18.8 \\
\hline \multicolumn{4}{|c|}{ Father's educational } \\
\hline & No formal education & 90 & 29.1 \\
\hline & Primary & 27 & 8.7 \\
\hline & Secondary & 95 & 30.7 \\
\hline & Tertiary & 97 & 31.4 \\
\hline
\end{tabular}

Other: includes Ewes, Bimuobas, Gonjas, Sissalas, Gas

The knowledge assessment variables among the revealed that the majority $(76.7 \%)$ of the respondents study subjects on ECs are presented in Table 2. It was had ever heard about ECs. Also, $66.2 \%$ of the 
participants got their information about ECs through formal education, $11.4 \%$ of them had the information about ECs from their friends/relatives, $8.0 \%$ heard about ECs from the media, $8.0 \%$ heard about ECs from the internet, and $6.3 \%$ of the students got information on ECs from health professionals. Most of the participants $(82.2 \%)$ have heard about ECs for more than six (6) months before this study, while $17.8 \%$ of the students have only heard about EC less than six (6) months before the study.

To most of the participants $(66.4 \%)$, the best time for EC to work is taking the pills within 72 hours of unprotected sex, $25.2 \%$ of the students believed the best time for EC to work is taking the pills within 5 days of unprotected sex, a few $(0.7 \%)$ of them believed the ideal time should be within 24 hours, and $7.7 \%$ could not tell which time is best for the EC to work.

The majority $(56.4 \%)$ of the participants believed that the effectiveness of EC is between 75 to $99 \%$, $23.3 \%$ believed it is within 51 to $74 \%$, and $3.0 \%$ believed the effectiveness of EC is below $50 \%$. Also, $17.4 \%$ were not sure of the effectiveness of ECs. Moreover, only $38.7 \%$ of the respondents believed that ECs were safe, $28.9 \%$ did not think ECs were safe, and $32.5 \%$ of study subjects were not sure of the safety of ECs. Additionally, most of the study participants $(50.5 \%)$ believed that the number of doses of EC pills was 2 (twice). However, $40.5 \%$ believed it should be once, and $8.9 \%$ believed the recommended number of doses should be 3 (three). In the study, a majority $(67.0 \%)$ believed that the interval between the pills is 12 (twelve) hours, $17.9 \%$ of the respondents believed the interval is 6 (six) hours, $9.3 \%$ were not sure if there was any interval. Moreover, $5.7 \%$ believed there was no interval.

On the indicators for ECs, $69.6 \%$ of the participants mentioned that ECs are necessary after unprotected sex, $52.8 \%$ of the study participants cited unwanted pregnancy as an indicator, $68.0 \%$ of the study participants made mention of ruptured condoms as an indicator for the use of ECs, $62.1 \%$ of the study participants cited missed period as an indicator of EC, whilst $68.6 \%$ mentioned post-rape as an indicator for the use of ECs. On the avenue to obtain ECs, the majority $(88.7 \%)$ of the respondents mentioned health facilities or pharmacy as areas one could obtain ECs, 9.4\% believed ECs could be obtained from the market, and $1.9 \%$ of the study participants did not have an idea as to where to obtain the ECs (Table 2). From that assessment, a majority $(65.0 \%)$ of the participants showed sufficient knowledge of ECs (not shown in the Table).

Table 2: Knowledge of female students on emergency contraceptives

\begin{tabular}{llll}
\hline Variables & Categories & Frequencies & $\%$ \\
\hline Respondent heard about EC & Yes & 237 & 76.7 \\
& No & 72 & 23.3 \\
Place respondent heard about EC & & & \\
& Formal Education & 157 & 66.2 \\
& Media & 19 & 8.0 \\
& Internet & 19 & 8.0 \\
& Health professionals & 15 & 6.3 \\
& Friends/relatives & 27 & 11.4 \\
Time respondent heard of EC & & & \\
& $<6$ months & 31 & 17.8 \\
& $>6$ months & 143 & 82.2 \\
\hline \multirow{2}{*}{ Best time EC works } & & 190 & 66.4 \\
\hline
\end{tabular}




\begin{tabular}{|c|c|c|c|}
\hline \multirow{7}{*}{ Effectiveness of EC } & Within 5 days & 72 & 25.2 \\
\hline & Within 24 hours & 2 & 0.7 \\
\hline & I don't Know & 22 & 7.7 \\
\hline & 75 to $99 \%$ & 172 & 56.4 \\
\hline & 51 to $74 \%$ & 71 & 23.3 \\
\hline & $<50 \%$ & 9 & 3.0 \\
\hline & Not sure & 53 & 17.4 \\
\hline \multirow{4}{*}{$\mathrm{EC}$ is safe } & Not sure & 6 & 1.9 \\
\hline & Safe & 118 & 38.7 \\
\hline & Unsafe & 88 & 28.9 \\
\hline & Not sure & 99 & 32.5 \\
\hline \multirow[t]{2}{*}{$\begin{array}{l}\text { Recommended number of doses } \\
\text { of EC pills }\end{array}$} & One & 118 & 40.5 \\
\hline & Two & 147 & 50.5 \\
\hline \multirow{3}{*}{ Interval between EC pills } & Three & 26 & 8.9 \\
\hline & No interval & 16 & 5.7 \\
\hline & 6 hours & 50 & 17.9 \\
\hline \multirow{5}{*}{ Indicators of EC } & 12 hours & 187 & 67.0 \\
\hline & Not sure & 26 & 9.3 \\
\hline & After unprotected sex & 215 & 69.6 \\
\hline & $\begin{array}{l}\text { Unwanted pregnancy } \\
\text { rupture of condom during }\end{array}$ & 163 & 52.8 \\
\hline & $\operatorname{sex}$ & 210 & 68.0 \\
\hline \multirow{5}{*}{ Place one can obtain EC } & Missed period & 192 & 62.1 \\
\hline & Post rape & 212 & 68.6 \\
\hline & & & \\
\hline & Market & 29 & 9.4 \\
\hline & Health facilities/pharmacy & 274 & 88.7 \\
\hline
\end{tabular}

Due to nonresponses, the totals of some variables may be less than the sample size (309). Indicators of EC: responses are not mutually exclusive thus; the total of the responses is greater than 309 (sample size). Also, due to nonresponses, the totals of some of the variables may be less than the sample size (309).

The attitudes of the participants towards the use of ECs are shown in Table 3. From the analysis, a majority $(69.3 \%)$ of them disagreed that using EC will not cause infertility; only $24.3 \%$ agreed the use of EC will cause infertility. However, $6.5 \%$ were neutral. Also, a little over half $(53.1 \%)$ of the participants agreed that using ECs after unsafe sex is helpful however, $42.4 \%$ disagreed, and $4.5 \%$ remained neutral. Most of the participants (45.6\%) disagreed that the use of EC creates a lack of confidence between partners. Surprisingly, most

Shamsu-Deen et al., 2021: UDSIJD Vol 8(2)
$(48.5 \%)$ of the study subjects disagreed that it is a good idea to avail EC to all women.

Moreover, some (34.6\%) of the participants agreed that the use of EC was a sin. Also, when the participants were asked if EC could hurt a future baby (pregnancy) if it fails, $43.4 \%$ disagreed that the baby could be hurt if the EC fails after usage. In the present study, a little over half $(50.8 \%)$ of the participants disagreed with the future use of ECs. Also, $40.1 \%$ agreed ECs cannot protect one from sexually transmitted infection. It was also revealed 
$54.7 \%$ of the participants believed that ECs should be used only once every month. Also, more than half $(53.4 \%)$ agreed that EC pills cannot fail. Similarly, close to $59 \%$ of the participants disagreed that ECs cannot replace regular family planning options (Table 3). The overall attitude of the participants towards the use of ECs was estimated from the individual attitude responses. To compute this, a standard scoring scale was adapted from a previous study by Kgosiemang \& Blitz (2018), and modified for the purpose of the present study. In the end, participants who had a mean of 1.5 and above were said to have a good attitude towards ECs, and those who scored less than 1.5 (mean) were classified as having a poor attitude towards ECs. In that regard, $54.0 \%$ of the respondents had a good attitude towards ECs. Conversely, $46.0 \%$ of them had a poor attitude towards EC.
From the qualitative interviews, the views of the participants reechoed religion as a barrier to the use of EC. For instance, "As a nursing student, I understand the importance of emergency contraceptives to me but my religion will not permit me to use them. My religion has posed a serious challenge in using any form of contraceptives" (participant 1)

Another participant reported as follows:

"For me, I actually got to hear about it when I was having problems with menses. The doctor in advising me asked if I have ever used emergency contraceptive. I was innocent so the doctor explained to me what it was used for" (participant 2)

Table 3. Attitudes of female students towards the use of emergency contraceptives

\begin{tabular}{|c|c|c|c|}
\hline Variables & Agree & Neutral & Disagree \\
\hline Using EC will not cause infertility & $75(24.3 \%)$ & $20(6.5 \%)$ & $214(69.3 \%)$ \\
\hline Using EC after unsafe sex is helpful & $164(53.1 \%)$ & $14(4.5 \%)$ & $131(42.4 \%)$ \\
\hline EC creates lack of confidence between partner & $121(39.2 \%)$ & $47(15.2 \%)$ & $141(45.6 \%)$ \\
\hline Good idea to avail EC to all women & $123(39.8 \%)$ & $50(16.8 \%)$ & $150(48.5 \%)$ \\
\hline Sin to use EC method & $107(34.6 \%)$ & $52(16.8 \%$ & $150(48.5 \%)$ \\
\hline Believe EC may hurt baby if it does not work & $120(38.8 \%)$ & $55(17.8 \%)$ & $134(43.4 \%)$ \\
\hline Willingness to use $\mathrm{EC}$ in the near future & $96(31.1 \%)$ & $56(18.1 \%)$ & $157(50.8 \%)$ \\
\hline $\begin{array}{l}\text { Emergency contraceptives cannot protect you from } \\
\text { sexually transmitted infections. }\end{array}$ & $124(40.1 \%)$ & $49(15.9 \%)$ & $136(44.0 \%)$ \\
\hline $\begin{array}{l}\text { Emergency contraceptives should be used only once } \\
\text { every month. }\end{array}$ & $83(26.9 \%)$ & $57(18.4 \%)$ & $169(54.7 \%)$ \\
\hline Emergency contraceptive pills can fail. & $98(31.7 \%)$ & $46(14.9 \%)$ & $165(53.4 \%)$ \\
\hline $\begin{array}{l}\text { Emergency contraception cannot be used as a regular } \\
\text { form of Family Planning taken after unprotected sex. }\end{array}$ & $70(22.7 \%)$ & $58(18.8 \%)$ & $181(58.6 \%)$ \\
\hline
\end{tabular}

The response variables are not mutually exclusive so, the totals for each variable may be greater than the sample size (309). 
The reasons for not using EC are presented in Figure 2 below. It was observed that $26.6 \%$ of the participants wanted pregnancy, $18.1 \%$ had no knowledge about EC, and $4.3 \%$ had their partners opposing the use of EC. Also, some $(37.2 \%)$ of the respondents stated religion as the reason for not using EC, and $13.8 \%$ stated fear of pregnancy. Findings from the qualitative interviews reaffirmed the quantitative data. For example, in an interview with one of the respondents she reported as follows: "I have knowledge of emergency contraceptives but my challenge is how to access it. I find it difficult going to the pharmacy shop to buy it, the way people around will perceive me".

Another participant has said "Ooh the nurse attitude toward those who are taking these emergency contraceptive pills is very bad. They also gossip about you”.

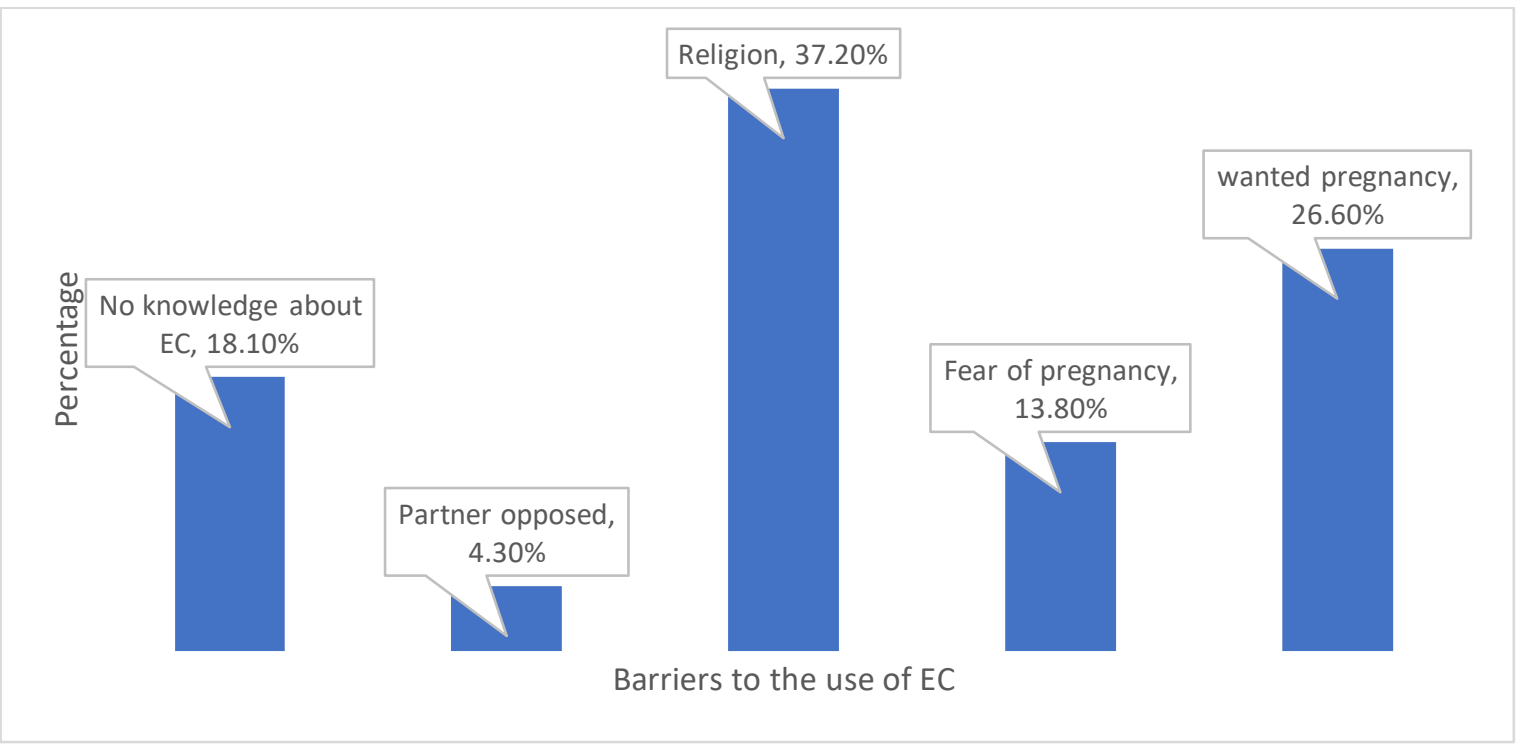

Figure 2. Reasons for not using emergency contraceptives

\section{Discussion}

It is common for young females in tertiary institutions to engage in high risk sexual behaviors without the use of a condom (Abdissa et al., 2017). In the present study, majority of the participants $(65.0 \%)$ had sufficient knowledge of ECs. The result was a little lower than the $70.0 \%$ reported from Ethiopia (Mishore et al., 2019), however, it was higher than the $52.8 \%$ reported from Botswana (Kgosiemang \& Blitz, 2018). The reasons for the observed disparity are not clear. However, differences in the characteristics of the study participants may have partly explained such variations. In this study, the main source of information on ECs was academic institutions. A similar finding was reported in a study involving female university students in Ethiopia (Mishore et al., 2019). Conversely, an earlier study conducted among students of the University of Cape Coast, Ghana, revealed that the main source of information on ECs was the radio (Darteh \& Doku, 2016). Similarly, another cross-sectional study found that the main source of information among female university students was the mass media (Dangachew, 2017). Differences in certain respondent characteristics such as socioeconomic factors may have partly explained the variations in the results.

The correct timing for the use of ECs following unprotected sex may be important for its efficacy to be realized (Gemzell-Danielsson \& Marions, 2004; Landgren et al., 1989; World Health Organization, 2020). The present study found that 
the vast majority of the respondents knew the right timing of the use of ECs. Similarly, an earlier study conducted in Nigeria showed that over $80 \%$ of the participants could identify the correct timeframe for the use of any method of EC (Fekadu, 2017). However, in Ethiopia, a very low knowledge level of the correct timeframe for the utilization of ECs was reported $18.5 \%$ (Abate et al., 2014).

The majority of the participants in the present study knew the percentage effectiveness of ECs. A study by Mishore et al.(2019) reported similar results, in which they found that the majority of the participants included in the study knew the right percentage effectiveness of ECs. On the indicators for the use of ECs, the respondents cited after unprotected sex, post rape, and ruptured condoms. Surprisingly, a high percentage of the participants cited 'unwanted pregnancy' and 'missed period' as indicators. This finding differed markedly from the result of a study in Botswana, in which majority pointed out 'missed period' as an inappropriate situation to use any form of EC (Kgosiemang \& Blitz, 2018). This is because missed periods may imply the conception has already taken place. Hence, EC may not be effective at this stage. In the present study, a majority of the respondents obtained ECs from health facilities or pharmacies. This finding was consistent with results reported by Mishore et al.(2019).

Overall, $54.0 \%$ of the participants had a good attitude toward ECs, which is relatively lower than a previous observation by Tilahun et al. (2011), in which the authors found that $62.9 \%$ of the students included in their study had a positive attitude towards ECs. Also, in Ethiopia, an earlier study found that $71.9 \%$ of the respondents had a favorable attitude towards the utilization of ECs (Dangachew, 2017). In contrast, a previous study showed that the majority of the respondents had a negative attitude towards ECs utilization in Botswana (Kgosiemang \& Blitz, 2018).

In the present study, the majority of the students disagreed that availing EC to all women was a good idea. This observation corroborates a previous report (Mishore et al., 2019), in which the authors argued that availing ECs to all women could lead to an increased in risky sexual behavior with potential side effects. It was also revealed in this study that the majority of the students were not willing to use ECs in the future. This finding again differed from earlier reports in Ethiopia whereby a majority of the participants were willing to use ECs in the future (Fekadu, 2017). The reasons that may have accounted for the differences between the present findings and results from the Ethiopian study (Fekadu, 2017) are not clear. However, differences in the socio-cultural characteristics between the study participants may have partly explained the differences in the results. In the present study, religion was a barrier to the utilization of ECs. Similarly, findings from a previous study showed that in Botswana, religious affiliation was a barrier to the use ECs (Kgosiemang \& Blitz, 2018).

Although the findings of the present study suggest that majority of the participants showed good knowledge and attitude towards the use of ECs, unwillingness about a future utilization of ECs was also reported. Moreover, religion and partner opposition are important barriers to the use of ECs among the participants. Thus, we recommend that the University be used as a medium to educate and increase the awareness of EC among females within the reproductive age.

\section{Acknowledgement}

We are grateful to the Registrar of the University for Development Studies for the opportunity offered to interview the students. Also, we express our heartfelt thanks to all the faculty officials for providing official data for the study. We are also grateful to the participants for honouring the study.

\section{References}

Abate, M., Assefa, N., \& Alemayehu, T. (2014). Knowledge, attitude, practice, and determinants emergency contraceptive use among women seeking abortion services in dire dawa, ethiopia. PLoS ONE. 
https://doi.org/10.1371/journal.pone.0110008

Abdissa, B., Addisie, M., \& Seifu, W. (2017). Premarital Sexual Practices, Consequences and Associated Factors among Regular Undergraduate Female Students in Ambo University, Oromia Regional State, Central Ethiopia,2015. Health Science Journal. https://doi.org/10.21767/1791-809x.1000482

Abera, H. (2014). Knowledge, Attitude, Utilization of Emergency Contraceptive and Associated Factors among Female Students of Debre Markos Higher Institutions, Northwest Ethiopia, 2014. Family Medicine \& Medical Science Research. https://doi.org/10.4172/2327-4972.1000149

Addo, V. N., \& Tagoe-Darko, E. D. (2009). Knowledge, practices, and attitudes regarding emergency contraception among students at a university in Ghana. International Journal of Gynecology and Obstetrics. https://doi.org/10.1016/j.ijgo.2009.01.008

Ahmed, F. A., Moussa, K. M., Petterson, K. O., \& Asamoah, B. O. (2012). Assessing knowledge, attitude, and practice of emergency contraception: A cross-sectional study among Ethiopian undergraduate female students. BMC Public Health. https://doi.org/10.1186/1471-2458-12-110

Amalba, A., Mogre, V., Appiah, M. N., \& Mumuni, W. A. (2014). Awareness, use and associated factors of emergency contraceptive pills among women of reproductive age (15-49 years) in Tamale, Ghana. BMC Women's Health, 14(1), 114. https://doi.org/10.1186/1472-6874-14-114

Ameryoun, A., Meskarpour-Amiri, M., DezfuliNejad, M. L., Khoddami-Vishteh, H. R., \& Tofighi, S. (2011). The assessment of inequality on geographical distribution of non-cardiac intensive care beds in Iran. Iranian Journal of Public Health.

Ameyaw, E. K. (2018). Prevalence and correlates of unintended pregnancy in Ghana: Analysis of 2014 Ghana Demographic and Health Survey. Maternal Health, Neonatology and Perinatology, 4(1), 17. https://doi.org/10.1186/s40748-018-0085-1

Bahk, J., Yun, S. C., Kim, Y. mi, \& Khang, Y. H. (2015). Impact of unintended pregnancy on maternal mental health: A causal analysis using follow up data of the Panel Study on Korean Children (PSKC). BMC Pregnancy and Childbirth. https://doi.org/10.1186/s12884-015-0505-4

Baiden, F., Awini, E., \& Clerk, C. (2002). Perception of university students in Ghana about emergency contraception. Contraception, 66(1), 23-26. https://doi.org/10.1016/S00107824(02)00315-3

Bearak, J., Popinchalk, A., Alkema, L., \& Sedgh, G. (2018). Global, regional, and subregional trends in unintended pregnancy and its outcomes from 1990 to 2014: estimates from a Bayesian hierarchical model. The Lancet Global Health. https://doi.org/10.1016/S2214109X(18)30029-9

Byamugisha, J. K., Mirembe, F. M., Faxelid, E., \& Gemzell-Danielsson, K. (2006). Emergency contraception and fertility awareness among university students in Kampala, Uganda. African Health Sciences, 6(4), 194-200. https://doi.org/10.5555/afhs.2006.6.4.194

Charan, J., \& Biswas, T. (2013). How to calculate sample size for different study designs in medical research? Indian Journal of Psychological Medicine, 35(2), 121. https://doi.org/10.4103/0253-7176.116232

Dangachew, A. (2017). Assessment of Knowledge, Attitude and Practice of Emergency Contraceptive Use among Female Students in Harar Preparatory Schools, Harari Regional State, Eastern Ethiopia. Reproductive System \& Sexual Disorders. 
https://doi.org/10.4172/2161-038x.1000215

Darteh, E. K. M., \& Doku, D. T. (2016). Knowledge and Usage of Emergency Contraceptives Among University Students in Ghana. Journal of Community Health, 41(1), 15-21. https://doi.org/10.1007/s10900-015$0057-6$

Davis, P., Sarasveni, M., Krishnan, J., Bhat, L. D., \& Kodali, N. K. (2020). Knowledge and attitudes about the use of emergency contraception among college students in Tamil Nadu, India. Journal of the Egyptian Public Health Association, 95(1), 1. https://doi.org/10.1186/s42506-019-0030-9

Dorairajan, G., Chinnakali, P., \& Mohan, B. (2015). Knowledge, attitude \& factors affecting potential use of emergency contraception in college students in Puducherry, south India. The Indian Journal of Medical Research, 141(1), 122-124. https://doi.org/10.4103/0971-5916.154515

Fekadu, Y. (2017). Knowledge Attitude and Utilization of Emergency Contraception among Health Science and Medical Students of Arba Minch University, 2015. Journal of Womens Health Care, 06(04). https://doi.org/10.4172/2167-0420.1000383

Fikre, R., Amare, B., Tamiso, A., \& Alemayehu, A. (2020). Determinant of emergency contraceptive practice among female university students in Ethiopia: systematic review and meta-analysis. Contraception and Reproductive Medicine, 5(1), 18. https://doi.org/10.1186/s40834-020-00123-8

Finer, L. B., \& Henshaw, S. K. (2006). Disparities in Rates of Unintended Pregnancy In the United States, 1994 and 2001. Perspectives on Sexual and Reproductive Health. https://doi.org/10.1363/3809006

Ganatra, B., Gerdts, C., Rossier, C., Johnson, B. R., Tunçalp, Ö., Assifi, A., Sedgh, G., Singh, S., Bankole, A., Popinchalk, A., Bearak, J., Kang,
Z., \& Alkema, L. (2017). Global, regional, and subregional classification of abortions by safety, 2010-14: estimates from a Bayesian hierarchical model. The Lancet. https://doi.org/10.1016/S01406736(17)31794-4

Gebrehiwot, H., Gebrekidan, B., Berhe, H., \& Kidanu, K. (2013). Assessment of knowledge, attitude, and practice towards emergency contraceptives among female college students at Mekelle town, Tigray region, Ethiopia: A cross sectional study. International Journal of Pharmaceutical Sciences and Research.

Gemzell-Danielsson, K., \& Marions, L. (2004). Mechanisms of action of mifepristone and levonorgestrel when used for emergency contraception. In Human Reproduction Update. https://doi.org/10.1093/humupd/dmh027

Kgosiemang, B., \& Blitz, J. (2018). Emergency contraceptive knowledge, attitudes and practices among female students at the University of Botswana: A descriptive survey. African Journal of Primary Health Care \& Family Medicine, 10(1), e1-e6. https://doi.org/10.4102/phcfm.v10i1.1674

Lakha, F., \& Glasier, A. (2006). Unintended pregnancy and use of emergency contraception among a large cohort of women attending for antenatal care or abortion in Scotland. The Lancet, 368(9549), 1782-1787. https://doi.org/10.1016/S01406736(06)69737-7

Landgren, B. M., Johannisson, E., Aedo, A. R., Kumar, A., \& Shi, Y. en. (1989). The effect of levonorgestrel administered in large doses at different stages of the cycle on ovarian function and endometrial morphology. Contraception. https://doi.org/10.1016/00107824(89)90060-7

Le, H. H., Connolly, M. P., Bahamondes, L., Cecatti, J. G., Yu, J., \& Hu, H. X. (2014). The burden of unintended pregnancies in Brazil: A 
social and public health system cost analysis. International Journal of Women's Health. https://doi.org/10.2147/IJWH.S61543

Major, B., Appelbaum, M., Beckman, L., Dutton, M. A., Russo, N. F., \& West, C. (2009). Abortion and Mental Health: Evaluating the Evidence. American Psychologist. https://doi.org/10.1037/a0017497

Mekonnen, G., Wendmagegn, N., \& Gebiru, D. (2017). The Usage of Emergency Contraceptive Methods of Female Students in Hawassa University: A Case Study on Natural and Computational Science. American Journal of Theoretical and Applied Statistics, $6(1), 61-71$.

Mishore, K. M., Woldemariam, A. D., \& Huluka, S. A. (2019). Emergency Contraceptives: Knowledge and Practice towards Its Use among Ethiopian Female College Graduating Students. International Journal of Reproductive Medicine. https://doi.org/10.1155/2019/9397876

Nasir, T., \& Pharm, B. (2010). KNOWLEDGE, ATTITUDE AND PRACTICE OF EMERGENCY CONTRACEPTION AMONG GRADUATING FEMALE STUDENTS OF JIMMA UNIVERSITY, SOUTHWEST ETHIOPIA. Ethiop $J$ Health Sci., 20(2), 91-97.

Sedgh, G., Singh, S., \& Hussain, R. (2014). Intended and Unintended Pregnancies Worldwide in 2012 and Recent Trends. Studies in Family Planning, 45(3), 301-314. https://doi.org/10.1111/j.1728-

4465.2014.00393.x

Shiferaw, B. Z., Gashaw, B. T., \& Tesso, F. Y. (2016). Knowledge, Attitude and Practice of Emergency Contraceptives among MizanTepi University Female Students, South West Ethiopia. Journal of Pain Management \& Medicine. $\quad$ https://doi.org/10.35248/26841320.16.2.111
SmithBattle, L., \& Leonard, V. (2012). Inequities Compounded: Explaining Variations in the Transition to Adulthood for Teen Mothers' Offspring. Journal of Family Nursing. https://doi.org/10.1177/1074840712443871

Sonfield, A., Kost, K., Gold, R. B., \& Finer, L. B. (2011). The Public Costs of Births Resulting from Unintended Pregnancies: National and State-Level Estimates. Perspectives on Sexual and Reproductive Health. https://doi.org/10.1363/4309411

Tamire, W., \& Enqueselassie, F. (2007). Knowledge, attitude, and practice on emergency contraceptives among female university students in Addis Ababa, Ethiopia. Ethiopian Journal of Health Development. https://doi.org/10.4314/ejhd.v21i2.10037

Tesfa, A. (2015). Assessment of Knowledge, Attitude and Practice Towards Emergency Contraceptive Methods Among Female Students in Seto Semero High School, Jimma Town, South West Ethiopia. Science Journal of Public Health. https://doi.org/10.11648/j.sjph.20150304.15

Tessema, M., \& Hinsermu, B. (2015). Knowledge, Attitude and Practice on Emergency Contraception and Associated Factors among Female Students of Debre-Markos University, Debre-Markos Town, East Gojam Zone, North West Ethiopia, 2013. Global Journal of Medical Research: E Gynecology and Obstetrics, 15(1). https://globaljournals.org/GJMR_Volume15/ 1-Knowledge-Attitude-and-Practice.pdf

Thomas, C. M., \& Cameron, S. (2013). Can we reduce costs and prevent more unintended pregnancies? A cost of illness and costeffectiveness study comparing two methods of EHC. BMJ Open, 3(12), e003815. https://doi.org/10.1136/bmjopen-2013003815

Tilahun, D., Assefa, T., \& Belachew, T. (2011). Knowledge, Attitude and Practice of 
Emergency Contraceptives among Adama University Female Students, Ethiopia. Ethiopian Journal of Health Sciences. https://doi.org/10.4314/ejhs.v20i3.69449

Trussell, J. (2007). The cost of unintended pregnancy in the United States. In Contraception.

https://doi.org/10.1016/j.contraception.2006. 11.009

World Health Organization. (2020). Emergency Contraception.

Yen, S., Parmar, D. D., Lin, E. L., \& Ammerman, S. (2015). Emergency Contraception Pill Awareness and Knowledge in Uninsured Adolescents: High Rates of Misconceptions Concerning Indications for Use, Side Effects, and Access. Journal of Pediatric and Adolescent Gynecology, 28(5), 337-342. https://doi.org/10.1016/j.jpag.2014.09.018 